\title{
Losses Computation in Reciprocating Tubular Permanent Magnet Generator with SMC Core
}

\author{
Behrooz Rezaeealam \\ Department of Electrical Engineering, Lorestan University, Iran
}

\begin{tabular}{|c|c|}
\hline Article Info & ABSTRACT \\
\hline Article history: & \multirow{6}{*}{$\begin{array}{l}\text { Generally, the Permanent Magnet Tubular Generators (PMTG) are employed } \\
\text { in the free-piston generator systems. In this paper, the PMTG with the core } \\
\text { made of Soft Magnetic Composite (SMC) is employed, and then, the PMTG } \\
\text { with the solid SMC core has cylindrical symmetry and also the outer } \\
\text { diameter of the machine reduces in comparison to the ones with multipart } \\
\text { laminated steel cores in which each part is radially placed along the air-gap } \\
\text { and there is unexploited space between them. Here, a Finite Element Method } \\
\text { (FEM) is developed in which the reciprocating motion of the translator is } \\
\text { considered by moving mesh techniques and moreover, the Jiles-Atherton } \\
\text { (JA) scalar hysteresis model is incorporated in the FE model to take into } \\
\text { account the hysteresis losses. Then, the copper and core losses are computed } \\
\text { and the equivalent circuit of the generator is derived. The calculated losses } \\
\text { are compared with the ones obtained from the analytical methods. }\end{array}$} \\
\hline Received Jun 28, 2018 & \\
\hline Revised Sep 5, 2018 & \\
\hline Accepted Sep 10, 2018 & \\
\hline Keyword: & \\
\hline $\begin{array}{l}\text { FEM } \\
\text { J-A hysteresis model } \\
\text { Permanent magnet tubular } \\
\text { Generator }\end{array}$ & \\
\hline $\mathrm{SMC}$ & \\
\hline
\end{tabular}

Copyright @ 2018 Institute of Advanced Engineering and Science. All rights reserved.

\section{Corresponding Author:}

Behrooz Rezaeealam,

Departement of Electrical Engineering,

Lorestan University,

Khorramabad, Lorestan 68151-44316, Iran.

Email: rezaee.bh@lu.ac.ir

\section{INTRODUCTION}

In recent years, the importance and applications of linear electric machines has been increased, drastically. Similar to the rotating electric machines, the linear electric machines are also divided into different types in terms of principles of their performance. The reciprocating permanent magnet (PM) linear electric machines have been found the more importance due to having the high force density, high efficiency, and simple control configuration [1],[2]. The reciprocating PMTG in which the crank shaft is omitted, is known as the free-piston generator. For this reason, the mechanical loss is low in the reciprocating PMTG. These electric machines can be used in hybrid electric vehicles [3] and for electricity generation from sea waves [4],[5].

In previous researches, the more attentions have been paid on the configurations and mechanical problems of free-piston generators, and the loss calculation has not received much attention [6]. The exact analytical modeling of linear electric machines is laborious due to their complex configuration [7], [8]. For this reason, the finite element method (FEM) is used in this paper for modeling the reciprocating PMTG with SMC core. The aim of this research is the consideration of iron loss in free-piston generators with the SMC core. The SMC material has high hysteresis losses, and so considering the hysteresis loop is very important for modeling the free-piston generators with the SMC core. The J-A method is used for modeling the hysteresis loop. In this research, the SMC core is used for the first time, and with respect to the specific features of SMC material, in addition to the loss calculation, the synchronous inductance is calculated, the equivalent circuit is extracted, and finally the characteristic of voltage, output power and the input power in terms of displacement is also drawn. 
The COMSOL software package is used for simulation by FEM. For verification the parameters used in simulation, the analytically calculated loss is compared with the corresponding results obtained through FEM.

This paper is organized as follows: the configuration of reciprocating PMTG, and the parameters used in FEM are introduced in section II. The techniques for loss calculation are also reviewed in section II. The results obtained through FEM are presented in section III. The losses are analytically calculated in section IV. The synchronous inductance is calculated in section $\mathrm{V}$ and the equivalent circuit is then drawn. Section VI gives the conclusions.

\section{MACHINE CONFIGURATION AND ANALYSIS METHOD}

The reciprocated PMTG analyzed in this paper was introduced in [3]. This generator is used in the combustion motor of hybrid vehicles as the free-piston generator. Figure 1 shows the configuration of this generator. The winding of this generator includes 6 coils connected in series, and its translator has 4 PM poles with alternative polarities. The only possibility for manufacturing the tubular stator core with laminated ferromagnetic materials is shown in Figure 2 [9],[10]. In this research, material SMC-Somaloy500 is used to manufacture the solid tubular core. SMC has specific features such as negligible eddy-current losses, flexibility in getting form, the suitable cost, and high Curie temperature [11].

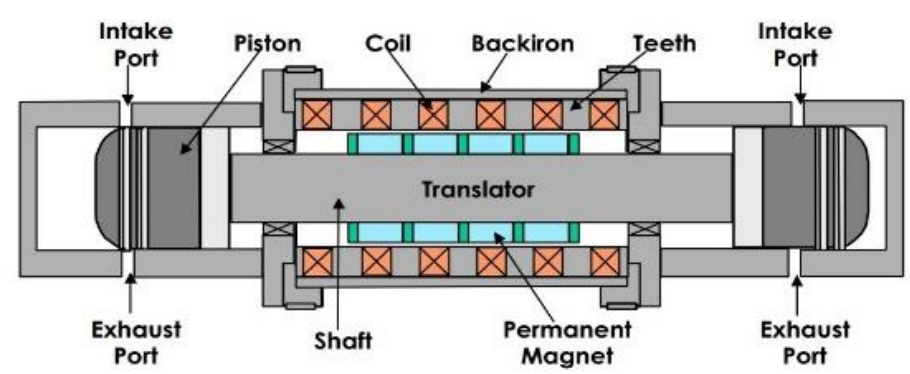

Figure 1. Reciprocating PMTG in free-piston generator system

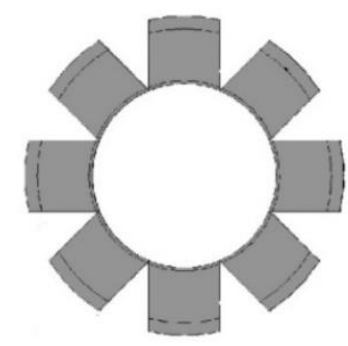

Figure 2. Laminated axial view of tubular machines

The hysteresis losses of translator have been ignored. The specifications of this machine are presented in Table 1. As shown in Figure 3, the displacement profile of translator along its axis is sinusoidal with angular speed $150 \mathrm{rad} / \mathrm{sec}$. Figure 4 shows the B-H curve of core material [12]. The resistive load $150 \Omega$ is connected to terminal of generator. 
Table 1. The PMTG specifications

\begin{tabular}{cc}
\hline Parameter & Value \\
\hline Output power & $116.9235 \mathrm{~W}$ \\
Output voltage & $102.0676 \mathrm{~V}$ \\
Pole number & 4 \\
Diameter & $135.5802 \mathrm{~m}$ \\
Turn number & 296 \\
PM thickness & $18.415 \mathrm{~mm}$ \\
PM length & $37.719 \mathrm{~mm}$ \\
Air-gap between adjacent PMs & $4.191 \mathrm{~mm}$ \\
Tooth width & $20 \mathrm{~mm}$ \\
Tooth depth & $20.955 \mathrm{~mm}$ \\
Slot width & $20 \mathrm{~mm}$ \\
Slot depth & $20.955 \mathrm{~mm}$ \\
Yoke width & $14.7066 \mathrm{~mm}$ \\
Core length & $251.46 \mathrm{~mm}$ \\
Air-gap length & $1.651 \mathrm{~mm}$ \\
Shaft diameter & $26.035 \mathrm{~mm}$ \\
PM remanence & $0.8 \mathrm{~T}$ \\
\hline
\end{tabular}

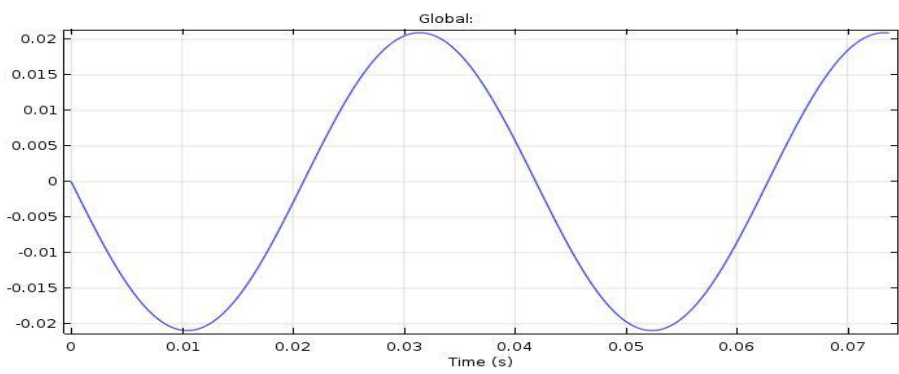

Figure 3. Displacement profile of translator

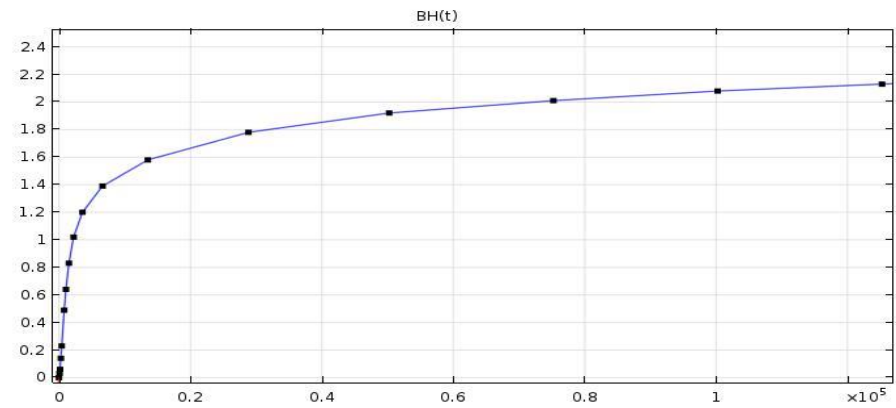

Figure 4. Anhysteretic Magnetization curve of SMC Somaloy500

\subsection{Modelling method and hysteresis loss calculation}

The most accurate method for hysteresis loss calculation is using the hysteresis loop. There are two existent methods of preisach [13] and Jiles-Atherton (J-A) [14] for considering the hysteresis loop. The J-A model is more feasible and simple than preisach model while considering the sinusoidal excitation and the SMC material. Under this condition, the computation time of FEM by J-A is the half of it by preisach model [13]. Therefore, the J-A method is used in this paper for modeling the hysteresis [15]. The vector equations of J-A method are as follows:

$$
\begin{aligned}
\frac{d M}{d t} & =c \cdot \frac{d M_{a n}}{d t}+(1-c) \cdot \frac{d M_{i r r}}{d t} \\
M_{a n, i} & =M_{s, i}\left[\operatorname{coth} \frac{|H e|}{a_{i}}-\frac{a_{i}}{\left|H_{e}\right|}\right] \frac{H_{e, i}}{\left|H_{e}\right|}
\end{aligned}
$$


$H_{e}=H+\alpha \cdot M$

$$
\begin{aligned}
& \frac{d M_{i r r}}{d t}=\left[\left(k^{-1} \cdot c^{-1} \cdot M_{r e v}\right) \cdot \frac{d H_{e}}{d t}\right]^{+} \frac{K^{-1} \cdot c^{-1} \cdot M_{r e v}}{\left|k^{-1} \cdot c^{-1} \cdot M_{r e v}\right|} \\
& M_{r e v}=c \cdot(c-1)^{-1} \cdot\left(M-M_{a n}\right)
\end{aligned}
$$

$M, M_{a n}, M_{i r r}$ and $M_{r e v}$ are the total magnetization, the anhysteretic magnetization, the irreversible magnetization and the reversible magnetization, respectively. Also, $H$ and $H_{e}$ represent the magnetic field vector and the effective magnetic field, respectively. Here, COMSOL Multiphysics Software is employed in which the corresponding external electrical circuit is coupled to the electromagnetic equations that are formulated based on the magnetic vector potential, and regarding the implementation of the above mentioned equations, more details can be found in [16]. Empirical parameters $M_{\mathrm{s}}, a, \alpha, \mathrm{k}$ and $c$ are the parameters of the $\mathrm{J}$-A hysteresis model, whose values are extracted from experiments [17].

\section{FEM RESULTS}

Figure 5 shows the refined mesh of the geometry. The flux density distribution of reciprocating PMTG is shown in Figure 6. As shown, the maximum flux density occurs when the translator is in the middle position, and the minimum flux density also occurs when the translator is in the end positions. Figure 7 shows the flux tube distribution in the core.

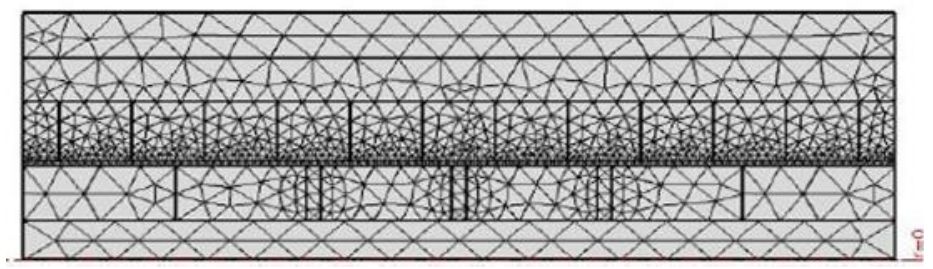

Figure 5. FEM mesh of the PMTG mode

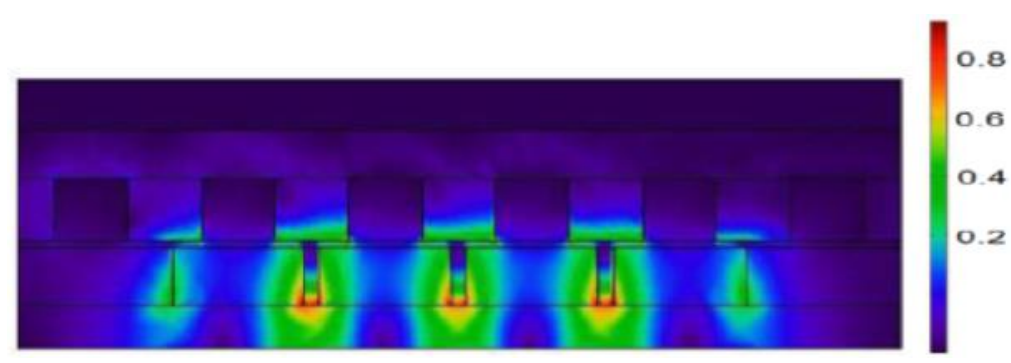

Figure 6. Flux density distribution

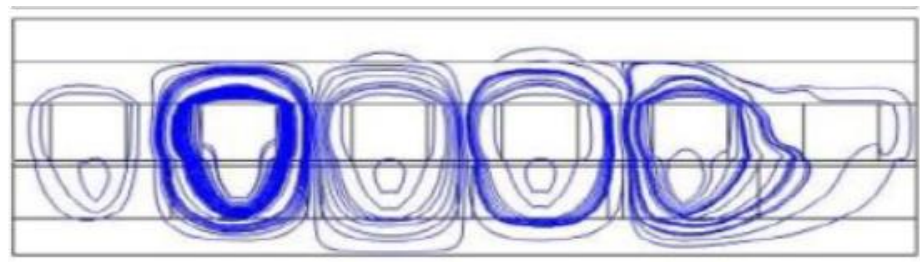

Figure 7. Magnetic flux tubes 
The hysteresis loop for each tooth is different from other teeth. Therefore, the hysteresis loss should be calculated for each tooth, separately. Since the magnetic flux density in yoke is affected by teeth, so the hysteresis loop should be extracted for each part of yoke, separately. Figure 8 shows the hysteresis loop for middle tooth. The hysteresis loss is calculated as follows:

$$
P_{h}=\left(\int_{0}^{T}\left(\int_{v c o r e} H_{r} \frac{d B_{r}}{d t} d v+\int_{v c o r e} H_{z} \frac{d B_{z}}{d t} d v\right) d t\right) \times f
$$

where $P_{h}$ is the hysteresis loss, $B$ is the magnetic flux density, $v_{\text {core }}$ is the volume of the core, and $f=1 / T$ is the frequency. The sum of area of the hysteresis loop in radial and vertical directions is equal to the hysteresis loss energy. For the analyzed PMTG in this paper $P_{h}=5.177$ (watt).

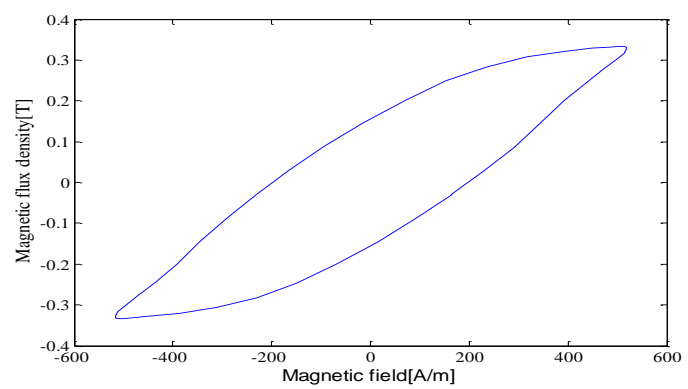

Figure 8 . The hysteresis loop in the middle tooth in radial direction

The core of stator and translator should be manufactured in solid form due to the configuration of reciprocating PMTG, and consequently the eddy-current loss is high. For this PMTG, total eddy current loss is low (0.562 watt) due to using the SMC material in stator and translator cores. The eddy-current loss is calculated as follows:

$$
P_{e}=\frac{j^{2}}{\sigma}
$$

where $\sigma$ is the conductivity coefficient of SMC, and $j$ is the electric current density in the core.

The copper loss is 3.56 (watt) for this PMTG, and the total resistance of coils is 4.295 ( $\Omega$ ). In this research, the skin effect is neglected. Figure 9 shows the profile of input force in terms of displacement of translator in one reciprocating cycle, and Figure 10 shows the load voltage.

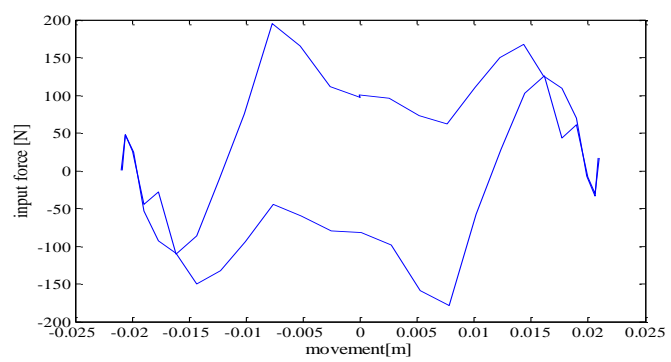

Figure 9. Input force versus displacement

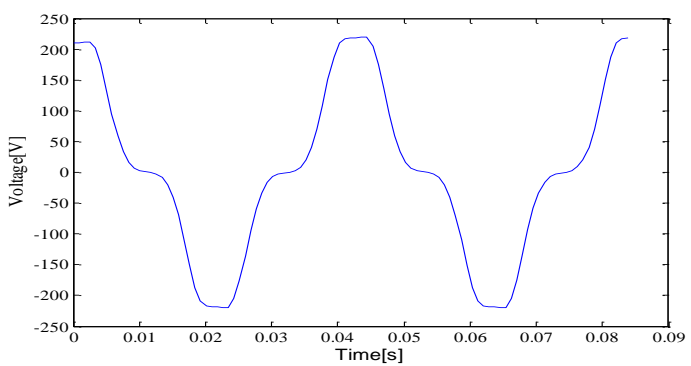

Figure 10. Output voltage

\section{ANALYTICAL CALCULATION OF LOSSES}

The losses are only calculated in stator core and the losses in the translator part are negligible. The total losses include the iron and copper losses, and the iron loss is also including the eddy-current and hysteresis losses. 
The iron loss is calculated by using the equation extracted from the catalog of SMC material. To calculate the iron loss, the stator core is divided into different parts with respect to the flux density distribution. Since the stator core is including the yoke and tooth parts, the maximum flux density in each part is calculated by using the analytical method presented in [18]. Figure 11 shows the core partitioning for calculating the core loss analytically:

$$
\begin{aligned}
& P_{F E}=\sum_{m=1}^{M} P_{h}+P_{e}+P_{e x} \\
& P_{F E}=K_{h} f B_{m}^{1.75}+K_{e p} f^{2} B_{m}^{2}+\frac{B_{m}^{2} f^{2} d^{2}}{8.1 \times \rho \times \text { resistivity } \times 1000}
\end{aligned}
$$

The comparison of results obtained through analytical method and FEM is shown in Figure 12. The resistance and copper loss of coils can be calculated while having the turn number, the cross sectional area, and conductivity of coils. The obtained value for resistance is $4.286(\Omega)$, and the copper loss is equal to 3.6 (watt). The analytically calculated loss including iron and copper loss is equal to 9.258 (watt).

\begin{tabular}{|l|l|l|l|l|l|l|l|l|l|l|l|}
\hline 3 & \multicolumn{2}{|c|}{2} & \multicolumn{5}{|c|}{1} & \multicolumn{3}{|c|}{2} & 3 \\
\hline 6 & & 5 & & 4 & & 4 & & 4 & & 5 & \\
\hline
\end{tabular}

Figure 11. Stator core partitioning for iron loss calculation

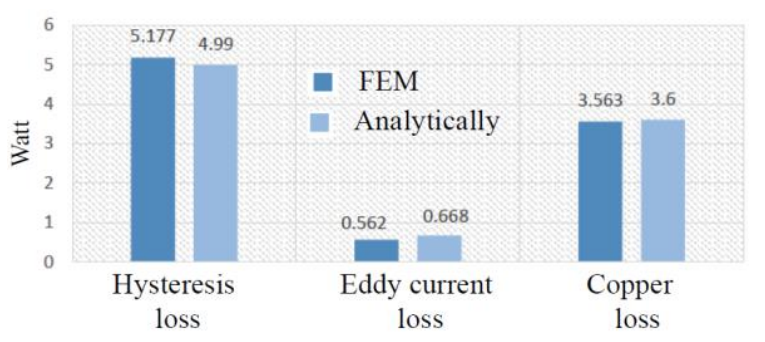

Figure 12. Loss comparison obtained through analytical method and FEM

\section{EQUIVALENT CIRCUIT OF THE RECIPROCATING SINGLE-PHASE PMTG}

Figure 13 shows the electric equivalent circuit of single-phase reciprocating PMTG in which Emf shows the electric motive force, $\mathrm{X}_{\mathrm{s}}$ is the synchronous reactance, and $\mathrm{R}_{\mathrm{s}}$ is the stator resistance:

$$
\begin{aligned}
& E m f=L_{s} \frac{d I_{a}}{d t}+R_{s} \times I_{a}+R_{\text {load }} \times I_{a} \\
& E m f=-N \frac{d \varphi}{d t}=-N \frac{d \varphi}{d z} \times \frac{d z}{d t}=-N \frac{d \varphi}{d z} \times v
\end{aligned}
$$

where $z, v$ and $\varphi$ are displacement, velocity and magnetic flux, respectively. The synchronous reactance is calculated by using the results obtained through short-circuit and open-circuit tests [19]. The obtained values of synchronous impedance and synchronous inductance are $16.87(\Omega)$ and $112(\mathrm{mH})$, respectively. 


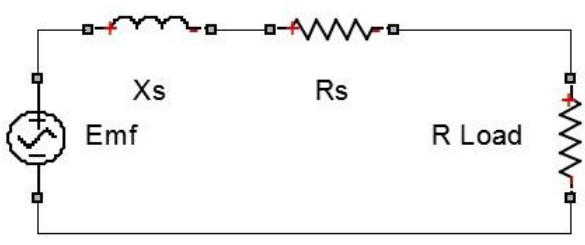

Figure 13. Equivalent circuit of single-phase reciprocating PMTG

\section{CONCLUSION}

In this paper, the studied reciprocating PMTG with solid SMC core was simulated and analyzed by using nonlinear transient 2-D FEM, in which the J-A model of magnetic hysteresis was incorporated and then, the hysteresis losses were calculated. Meanwhile, the eddy-current and copper losses were calculated. Due to using the SMC core, the eddy-current losses are negligible despite the using of solid core. The losses obtained through FEM agree well with the corresponding values calculated analytically. The electric equivalent circuit of the PMLG was also extracted. With respect to the obtained results in this paper, the using of SMC core in free-piston generators is recommended.

\section{REFERENCES}

[1] K. B. Jang, et al., "Iron loss calculation in a flux-concentration-type LOA," IEEE transactions on magnetics, vol/issue: 41(10), pp. 4024-4026, 2005.

[2] M. W. Zouaghi, et al., "Lumped circuit-based sizing of quasi-Halbach PM excited T-LSMs: application to free piston engines," IET Electric Power Applications, vol/issue: 11(4), pp. 557-566, 2017.

[3] W. R. Cawthorne, et al., "Development of a linear alternator-engine for hybrid electric vehicle applications," IEEE transactions on vehicular technology, vol/issue: 48(6), pp. 1797-1802, 1999.

[4] N. Shahabudin, et al., "Portable Pico Linear Generator Design with Different Magnet Shapes for Wave Energy Conversion System," International Journal of Power Electronics and Drive Systems, vol/issue: 8(1), pp. 360-366, 2017.

[5] B. Rezaeealam, "Permanent Magnet Tubular Generator with Quasi-Halbach Array for Free-Piston Generator System," International Journal of Power Electronics and Drive Systems, vol/issue: 8(4), pp. 1663-1672, 2017.

[6] N. B. Hung and O. Lim, "A review of free-piston linear engines," Applied Energy, vol. 178 pp. 78-97, 2016.

[7] J. Wang, et al., "A general framework for the analysis and design of tubular linear permanent magnet machines," IEEE Transactions on Magnetics, vol/issue: 35(3), pp. 1986-2000, 1999.

[8] H. Komijani, et al., "Modeling and state feedback controller design of tubular linear permanent magnet synchronous motor," International Journal of Power Electronics and Drive Systems, vol/issue: 7(4), pp. 14101419, 2016.

[9] J. Faiz, et al., "Reciprocating flux-concentrated induction generator for free-piston generator," IEEE transactions on magnetics, vol/issue: 42(9), pp. 2172-2178, 2006.

[10] J. Wang and D. Howe, "Influence of soft magnetic materials on the design and performance of tubular permanent magnet machines," IEEE Transactions on Magnetics, vol/issue: 41(10), pp. 4057-4059, 2005.

[11] H. Shokrollahi and K. Janghorban, "Soft magnetic composite materials (SMCs)," Journal of Materials Processing Technology, vol/issue: 189(1), pp. 1-12, 2007.

[12] http://www.hoganas.com, [Online]. Available: hogans, 2016.

[13] A. Benabou, et al., "Comparison of Preisach and Jiles-Atherton models to take into account hysteresis phenomenon for finite element analysis," Journal of magnetism and magnetic materials, vol/issue: 261(1), pp. 139$160,2003$.

[14] D. C. Jiles and D. L. Atherton, "Theory of ferromagnetic hysteresis," Journal of magnetism and magnetic materials, vol/issue: 61(1-2), pp. 48-60, 1986.

[15] A. J. Bergqvist, "A simple vector generalization of the Jiles-Atherton model of hysteresis," IEEE Transactions on Magnetics, vol/issue: 32(5), pp. 4213-4215, 1996.

[16] J. P. A. Bastos and N. Sadowski, "Electromagnetic Modeling by Finite Element Methods," New York, USA, Marcel Dekker, 2003.

[17] B. Zidaric and D. Miljavec, "JA hysteresis model parameters estimation using GA," Advances in electrical and electronic engineering, vol/issue: 4(3), pp. 174, 2005.

[18] J. Wang, et al., "Prediction and measurement of iron loss in a short-stroke, single-phase, tubular permanent magnet machine," IEEE Transactions on Magnetics, vol/issue: 46(6), pp. 1315-1318, 2010.

[19] A. E. Fitzgerald, et al., "Electric machinery," New York, McGraw-Hill, vol. 5, 2003. 